\title{
Review of the Panorpa wormaldi group (Mecoptera: Panorpidae), with descriptions of two new species
}

\author{
$\mathrm{Ji}^{-S h e n} \mathrm{WANG}^{\circledR 1, *}$ \& Tomoya SUZUKI ${ }^{\circledR 2}$ \\ ${ }^{1}$ College of Agriculture and Biological Sciences, Dali University, Dali 671003, P.R. China. \\ ${ }^{1}$ Tianlong Entomological Institute, Dali 671003, P.R. China. \\ ${ }^{2}$ Faculty of Science, Shinshu University, Matsumoto, Nagano 390-8621, Japan. \\ *Corresponding author: wangjishen826@gmail.com \\ 2Email: 10.3.t.suzuki@gmail.com \\ ${ }^{1}$ urn:lsid:zoobank.org:author:0C4FE92F-97C9-427C-B5F4-762A93A837EC \\ ${ }^{2}$ urn:lsid:zoobank.org:author:148BE82B-581C-4B5C-A4C9-A4C6D01A35C0
}

\begin{abstract}
Panorpa Linnaeus, 1758 is the largest genus in the scorpionfly family Panorpidae. In this paper, a taxonomic review of the Panorpa wormaldi group is provided, with two new species described from China: Panorpa fengyanga Wang \& Suzuki, sp. nov. from Zhejiang, and Panorpa zhuohengi Wang \& Suzuki, sp. nov. from Guangdong. The male of Panorpa implicata Cheng, 1957 is discovered and described for the first time. A distributional map and keys to species are also provided for this group. Species number in this group is updated from 17 to 19. In addition, their biogeographical and evolutionary implications are briefly discussed.
\end{abstract}

Keywords. Biodiversity, fauna, Oriental Region, scorpionflies, new species.

Wang J.-S. \& Suzuki T. 2022. Review of the Panorpa wormaldi group (Mecoptera: Panorpidae), with descriptions of two new species. European Journal of Taxonomy 794: 18-39. https://doi.org/10.5852/ejt.2022.794.1651

\section{Introduction}

Members of the family Panorpidae Latreille, 1802 are commonly called 'scorpionflies' due to their males' enlarged and recurved genitalia, which give a resemblance to the scorpion's stinger. Panorpa Linnaeus, 1758 is the largest genus in this family, with approximately 260 species distributed among Europe, Asia and North America. Recently, this genus is considered a paraphyletic group and probably deserves further split (Wang \& Hua 2021).

The Panorpa wormaldi group was firstly introduced by Issiki (1933) for six species from Japan (Honshu and Kyushu) and China (Taiwan). Members of this group are mainly characterized by: wings held rooflike over abdomen at repose, male gonostyli (= dististylus) very short, approximately half as long as gonocoxites, and female medigynium with a greatly sclerotized dorsal plate, greatly elongated posterior arms and axis, and poorly developed main plate. Subsequently, twelve similar species were described from China (Issiki 1927; Carpenter 1945; Issiki \& Cheng 1947; Cheng 1957; Byers 1970, 2002; Chou 
et al. 1987) and Japan (Issiki 1929; Miyamoto 1984, 1985; Nakamura 2009), and can be assigned into this group under Issiki's criteria. However, these species lack a comprehensive review, impeding a further revision of the genus Panorpa at a global scale.

In this study, we present a taxonomical revision of the $P$. wormaldi group, with two new species described from Guangdong and Zhejiang, China. The male of Panorpa implicata Cheng, 1957 is firstly discovered and described. A distributional map and keys to species are also provided. In addition, the biogeographical and evolutionary implications of this group are briefly discussed.

\section{Material and Methods}

All the material examined in this study is deposited in the Biological Science Museum, Dali University, Dali (DALU), or Sun Yat-sen University, Guangzhou (SYSU). Adult scorpionflies were caught with a collecting net, and preserved in 95\% ethanol or pinned. Photographs were taken with a Nikon D7000 digital camera in conjunction with a Nikkor AF-S Micro $105 \mathrm{~mm} \mathrm{f} / 2.8$ lens (Figs 1F, 2A-B, 3A-B, 4, $5 \mathrm{~A}-\mathrm{B}$ ), a Sony Alpha $77 \mathrm{II}$ digital camera in conjunction with a Sony $50 \mathrm{~mm} \mathrm{f} / 2.8$ macro lens (Fig. 1AE, G-I), or a Nikon D7000 digital camera in conjunction with a Canon MP-E $65 \mathrm{~mm} \mathrm{f} / 2.81-5 \mathrm{X}$ macro lens with a handmade mount adapter (other images). Measurements follow Wang \& Hua (2021). The female habitus images were modified to omit the left antennae, wings and legs. The map was obtained from SimpleMappr (http://www.simplemappr.net) and modified in Adobe Illustrator ver. CC to add distributional information. All pictures were adjusted and grouped with Adobe Photoshop ver. CC.

\section{Abbreviations for morphological terms used in the main text}

Terminology follows Mickoleit $(1975,1976)$ and Willmann (1989).

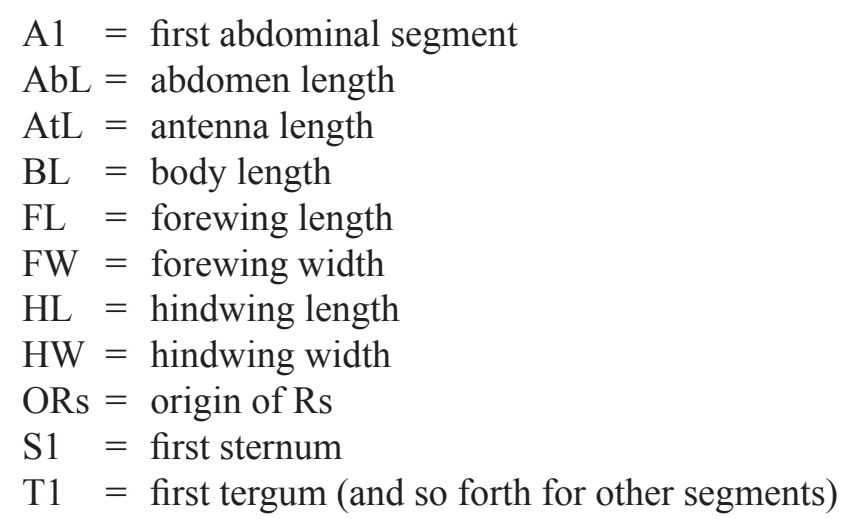

\section{Abbreviations for morphological terms used in the figures}

The male abdominal segments are indicated by Roman numerals.

$$
\begin{aligned}
\mathrm{Ae} & =\text { aedeagus } \\
\mathrm{Ap} & =\text { apodeme of axis } \\
\mathrm{Ax} & =\text { axis } \\
\mathrm{Ce} & =\text { cercus } \\
\mathrm{DPI} & =\text { dorsal plate } \\
\mathrm{DPr} & =\text { dorsal process } \\
\mathrm{DV} & =\text { dorsal valve } \\
\mathrm{Ep} & =\text { epandrium } \\
\mathrm{Gcx} & =\text { gonocoxite } \\
\mathrm{Gs} & =\text { gonostylus }
\end{aligned}
$$


$\mathrm{Hv}=$ hypovalve

$\mathrm{LPr}=$ lateral process

$\mathrm{MP}=$ main plate of medigynium

$\mathrm{PA}=$ posterior arm

$\mathrm{Pm}=$ paramere

$\mathrm{StH}=$ stalk of hypandrium

$\mathrm{StP}=$ stalk of paramere

$\mathrm{VV}=$ ventral valve

\section{Results}

\section{Taxonomy}

Class Insecta Linnaeus, 1758

Order Mecoptera Packard, 1886

Suborder Pistillifera Willmann, 1987

Superfamily Panorpoidea Latreille, 1802

Family Panorpidae Latreille, 1802

Subfamily Panorpinae Latreille, 1802

Genus Panorpa Linnaeus, 1758

The Panorpa wormaldi group sensu Issiki, 1933

Figs $1-6$

\section{Diagnosis}

This group of species was originally recognized by the following characters: 1) rostrum relatively short and stout; 2) wings held roof-like over abdomen at repose; in males, 3) gonostyli (= dististyli) very short, approximately half as long as gonocoxites; 4) parameres often furcated and bearing long stout spines; 5) aedeagus with lateral processes greatly elongated; and in females, 6) medigynium with a greatly sclerotized dorsal plate, greatly elongated posterior arms and axis, and poorly developed main plate.

\section{Distribution}

Oriental Region: China and Japan (Fig. 6).

Panorpa wormaldi MacLachlan, 1875

Figs 1A, 6

Panorpa Wormaldi (sic!) MacLachlan, 1875: 186 (type locality: Yokohama, Japan).

Panorpa Wormaldi (sic!) - Miyaké 1908: 1; 1910: 187; 1913: 358, pl. 31, fig. 14; pl. 36, fig. 18; text fig. $2 \mathrm{~m}$.

Panorpa wormaldi - Esben-Petersen 1915: 221; 1921: 37, figs 35-36; pl. 1, fig. 11. — Penny \& Byers 1979: 381. — Miyamoto 1985: 201, fig. 2g-h.; 1988: 42, fig. 13.

\section{Diagnosis}

This species is characterized by the following features: 1) wings with several slender transverse stripes arranged into two reversed Y-shaped patterns; and 2) male hypovalves slender with a blunt process at middle portion of inner margin, and tapering in distal half. 


\section{Distribution}

Japan: Honshu (Kanagawa, Nagano, Nara, Tokyo, and Yamanashi) (Fig. 6).

\section{Panorpa striata Miyaké, 1908}

Figs 1B, 6

Panorpa striata Miyaké, 1908: 6, pl. 1, figs 1, 1a-b (type locality: Japan).

Panorpa striata - Miyaké 1910: 187; 1913: 359, pl. 36, fig. 19; text fig. 2s. — Esben-Petersen 1915: 221; 1921: 38. - Penny \& Byers 1979: 380.

Aulops striata - Enderlein 1910: 390. — Miyamoto 1988: 42; 1994: 223.

\section{Diagnosis}

This species is similar to Panorpa wormaldi MacLachlan, 1875, but can be differentiated from the latter by the following characters: 1) wings with an additional short stripe between two reversed Y-shaped
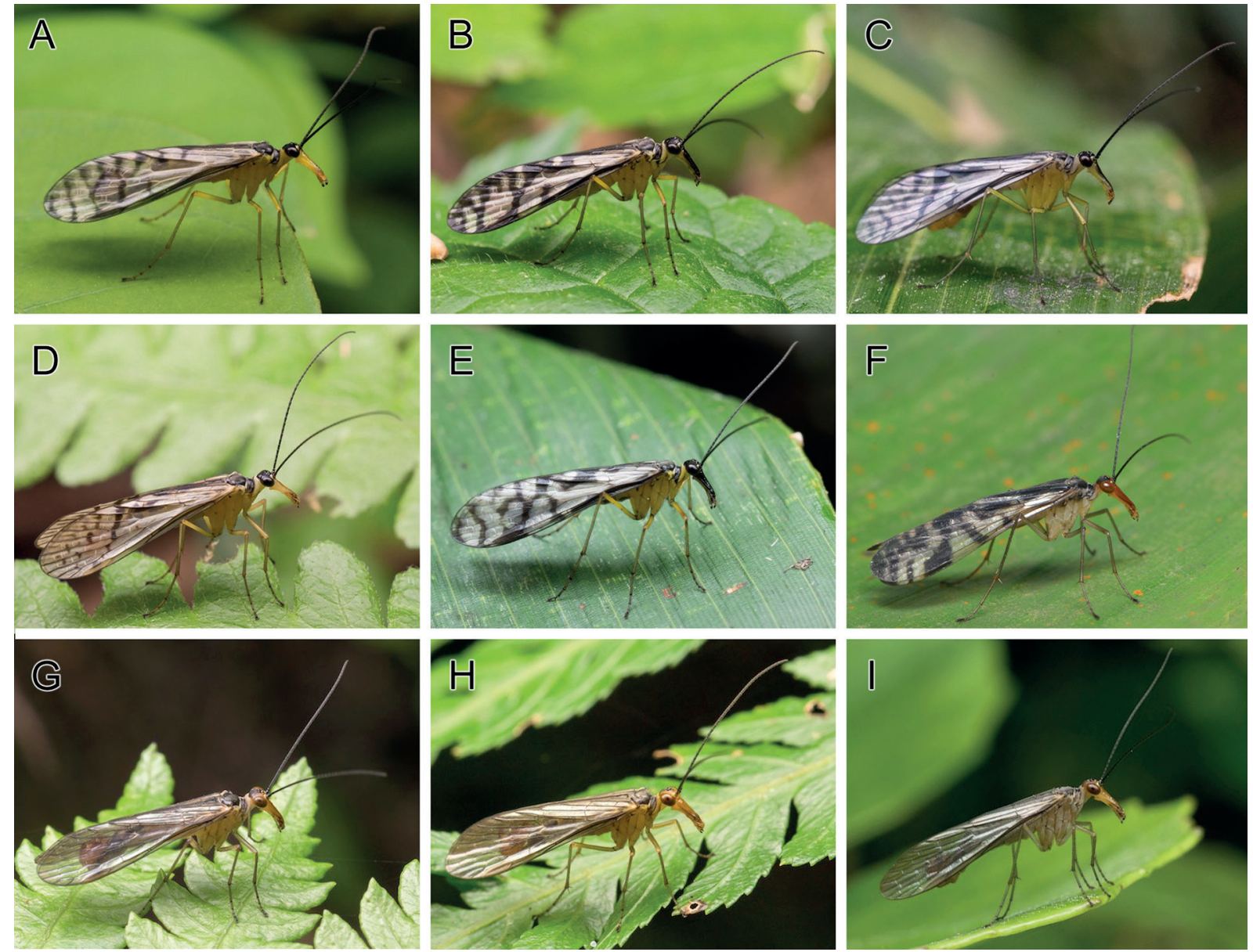

Fig. 1. Habitus of the Panorpa wormaldi group, males. A. Panorpa wormaldi MacLachlan, 1875. B. P. striata Miyaké, 1908. C. P. multifasciaria Miyaké, 1910. D. P. kiusiuensis Issiki, 1929. E. P. tsunekatanis Issiki, 1929. F. P. gressitti Byers, 1970. G. P. amamiensis Miyamoto \& Makihara, 1984. H. P. okinawaensis Nakamura, 2009. I. P. tokunoshimaensis Nakamura, 2009. CJi-Shen Wang (F) and Tomoya Suzuki (A-E, G-I). 
patterns along hind margin (cf. lacking such a stripe); and 2) male hypovalves greatly shortened and shorter than basal stalk of hypandrium (cf. longer).

\section{Distribution}

Japan: Shikoku (Ehime and Tokushima) (Fig. 6).

Panorpa multifasciaria Miyaké, 1910

Figs 1C, 6

Panorpa multifasciaria Miyaké, 1910: 196 (type locality: Gifu, Japan).

Panorpa multifasciaria - Miyaké 1913: 360, pl. 36, fig. 20. — Esben-Petersen 1915: 221; 1921: 38, figs 37-38; pl. 1, fig. 10. — Penny \& Byers 1979: 379. — Miyamoto 1988: 42. — Suzuki \& Suzuki 2015: 51, figs 1,3 .

\section{Diagnosis}

This species is very similar to Panorpa striata Miyaké, 1908 by the greatly shortened male hypovalves, but can be readily differentiated from the latter by the lack of two reversed Y-shaped patterns on the wings.

\section{Distribution}

Japan: Honshu (Gifu, Hiroshima, Hyōgo, Nagano, and Toyama) (Fig. 6).

\section{Panorpa ochraceocauda Issiki, 1927}

Fig. 6

Panorpa ochraceocauda Issiki, 1927: 3, fig. 3 (type locality: Tattaka (= Sungkang), Formosa (= Taiwan), China).

Panorpa ochraceocauda - Issiki \& Cheng 1947: 2. - Penny \& Byers 1979: 379. - Hsu et al. 1999: 153. — Byers 2002: 253. — Wang \& Hua 2018: 292, fig. 3-145-1.

\section{Diagnosis}

This species can be recognized by the following characters: 1) wings with greatly reduced markings represented by a spot-like pterostigmal band; and 2) male parameres trifurcated and concealed in gonocoxital cavity.

\section{Distribution}

China: Taiwan (Nantou) (Fig. 6).

Panorpa peterseana Issiki, 1927

Fig. 6

Panorpa peterseana Issiki, 1927: 2, fig. 2a-b (type locality: Shinsuiei (= Jinshuiying), Formosa (= Taiwan), China).

Panorpa peterseana - Issiki \& Cheng 1947: 11, figs 51-52. - Penny \& Byers 1979: 380. - Hsu et al. 1999: 153. - Wang \& Hua 2018: 296, figs 3-148-1, 3-148-2. — Bicha et al. 2020: 1001, fig. 2. 


\section{Diagnosis}

This species is characterized by the following combination of features: 1) yellow occiput with a tridentshaped dark brown pattern; 2) wing markings reduced with an oblique and often unbranched pterostigmal band; and 3) male parameres trifurcated, with dorsal branch greatly elongated beyond middle portion of gonostylus, and bearing numerous long spines along inner margin.

\section{Distribution}

China: Taiwan (Chiayi, Nantou, Pingtung) (Fig. 6).

\section{Panorpa kiusiuensis Issiki, 1929}

Figs 1D, 6

Panorpa kiusiuensis Issiki, 1929: 302, fig. 19 (type locality: Gokanoshō, Kiusiu (= Kyushu), Japan).

Panorpa kiusiuensis - Penny \& Byers 1979: 378. - Miyamoto 1988: 42, fig. 15. - Miyamoto \& Nakamura 2008: 232, pl. 88, fig. 1359.

\section{Diagnosis}

This species is superficially similar to Panorpa multifasciaria Miyaké, 1910, but can be readily differentiated from the latter by the following characters: 1) wing markings more reduced; and 2) male hypovalves long, almost as long as basal stalk of hypandrium (cf. shorter than basal stalk).

\section{Distribution}

Japan: Kyushu (Fukuoka, Kagoshima, Kumamoto, Oita, Saga) (Fig. 6).

Panorpa tsunekatanis Issiki, 1929

Figs 1E, 6

Panorpa tsunekatanis Issiki, 1929: 299, figs 17-18 (type locality: Kamikōchi, Shinano, Honsiu (= Honshu), Japan).

Panorpa tsunekatanis - Penny \& Byers 1979: 381. — Miyamoto 1988: 42. — Miyamoto \& Nakamura 2008: 232, pl. 88, fig. 1360.

\section{Diagnosis}

This species can be differentiated from its relatives by the following characters: 1) wing markings very dense with a small circular spot near ending of $\mathrm{CuP}$;2) male hypandrium with a pair of very long hypovalves nearly three times as long as basal stalk; and 3) male parameres bifurcated, with dorsal branch stout and ventral branch extremely delicate and clubbed apically.

\section{Distribution}

Japan: Honshu (Aichi, Ishikawa, Nagano, Niigata, Shinano, Toyama, and Yamanashi) (Fig. 6).

\section{Panorpa obliqua Carpenter, 1945}

Fig. 6

Panorpa obliqua Carpenter, 1945: 70, figs 2-3, 8; pl. 11, fig. 9 (type locality: Hong San (= Xiangshan), southeast Kiangsi (= Jiangxi), China). 
Panorpa obliqua - Cheng 1957: 36, figs 44-45, 97-98. — Penny \& Byers 1979: 379.

\section{Diagnosis}

This species can be differentiated from its relatives by the following characters: 1) wing markings dense, with elongated marginal spot connected to oblique pterostigmal band and forming a distinct V-shaped pattern; 2) male parameres greatly curved inward at apex; and 3) female medigynium with apodemes of axis short and slightly exceeding dorsal plate proximally.

\section{Distribution}

China: Jiangxi (Xunwu) (Fig. 6).

Panorpa longiramina Issiki \& Cheng, 1947

Fig. 6

Panorpa longiramina Issiki \& Cheng, 1947: 6, figs 9-11, 49-50 (type locality: Musha (= Wushe), Formosa (= Taiwan), China).

Panorpa longiramina - Issiki 1965: 245. - Penny \& Byers 1979: 379. - Hsu et al. 1999: 152. Byers 2002: 253. - Wang \& Hua 2018: 284.

\section{Diagnosis}

This species can be easily recognized by the following characters: 1) wing markings greatly reduced with only a small spot near pterostigma; 2) male parameres trifurcated and extending beyond apex of gonocoxites; and 3) female medigynium with posterior arms diamond-shaped and broadest approximately at middle.

\section{Distribution}

China: Taiwan (Chiayi, Nantou, Taitung) (Fig. 6).

Panorpa implicata Cheng, 1957

Figs 2, 6

Panorpa implicata Cheng, 1957: 37, figs 99, 103, 280 (type locality: Ta-chu-Lan (= Dazhulan), Shaowu Hsien (= Shaowu County), Fukien (= Fujian), China).

Panorpa implicata - Penny \& Byers 1979: 378. — Wang \& Hua 2018: 273, fig. 3-132-1.

\section{Diagnosis}

This species is superficially similar to Panorpa obliqua Carpenter, 1945, especially in the V-shaped marginal spot and pterostigmal band, but can be readily differentiated by the following characters: 1) wings with less dense markings, and basal band with a small anterior spot not reaching anterior margin (cf. more dense markings, and basal band with a large anterior spot reaching anterior margin); 2) male parameres bifurcated with a delicate and short ventral branch, and a strong dorsal branch reaching middle of gonostylus (cf. unfurcated and only reaching apex of gonocoxites); and 3) female medigynium with axis longer than posterior arms (cf. shorter). 


\section{Material examined}

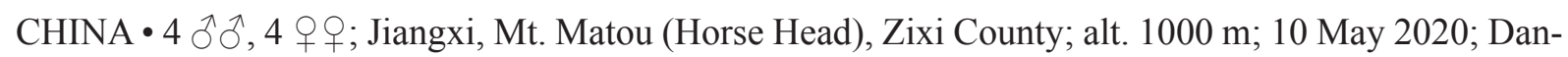
Chen Zhu leg.; DALU.

\section{Distribution}

China: Fujian (Shaowu) and Jiangxi (Zixi) (Fig. 6).

\section{Panorpa gressitti Byers, 1970}

Figs $1 \mathrm{~F}, 4 \mathrm{~A}-\mathrm{B}, 6$

Panorpa gressitti Byers, 1970: 390, figs 10-13 (type locality: Tao-Kok-Wan (= Caojiaowan), Lungtau Shan (= Mt. Longdou), Kwangtung (= Guangdong), China).

Panorpa gressitti - Penny \& Byers 1979: 378. — Wang \& Hua 2018: 268, fig. 3-129-1, 3-129-2.

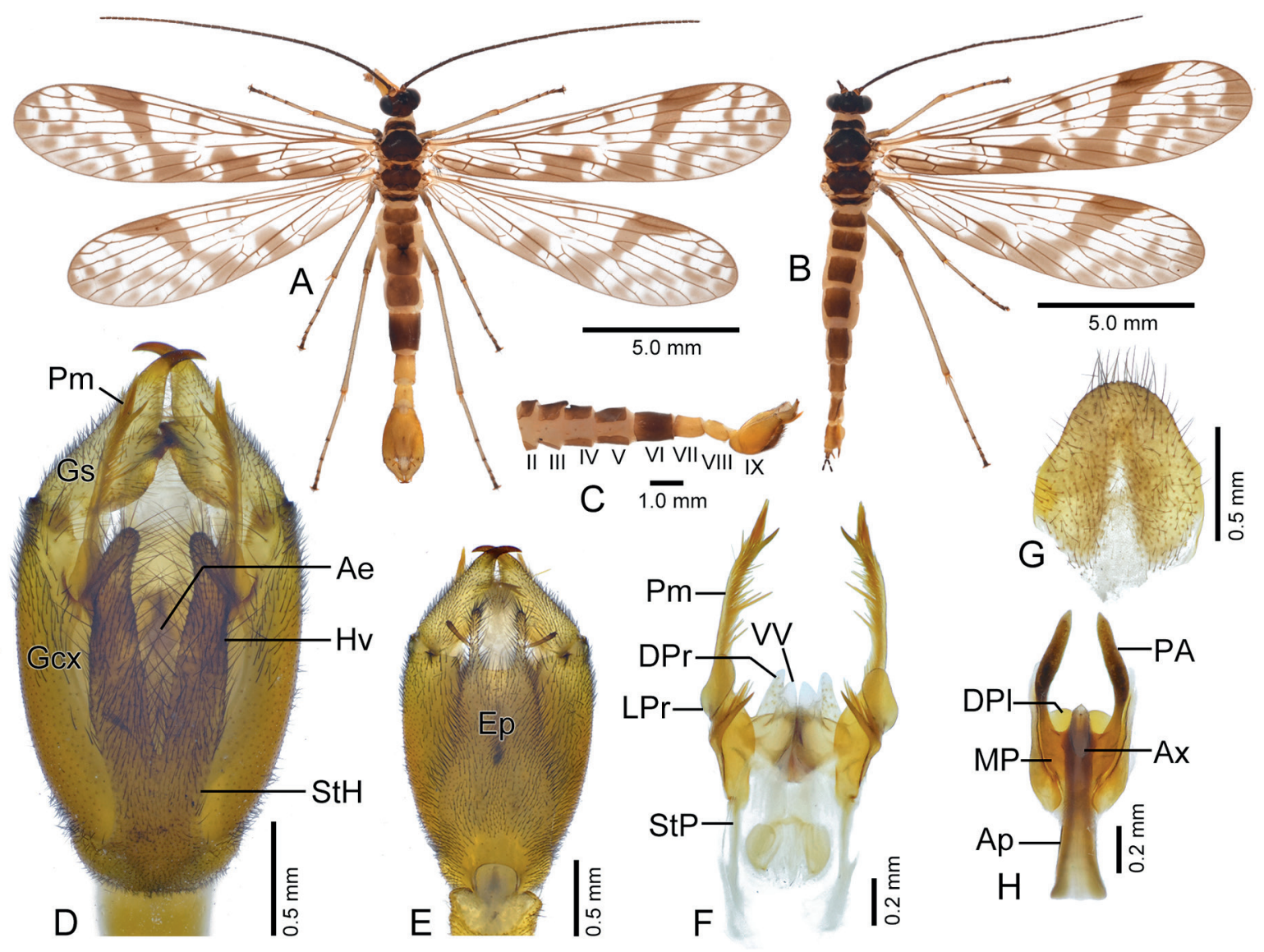

Fig. 2. Panorpa implicata Cheng, 1957. A, C-F. ठ (DALU). B, G-H. $q$ (DALU). A-B. Habitus, dorsal view. C. Abdomen, left-lateral view. D-E. Genital bulb, ventral and dorsal views, respectively. F. Aedeagal complex, ventral view. G. Subgenital plate, ventral view. H. Medigynium, ventral view. 


\section{Diagnosis}

This species is similar to Panorpa implicata Cheng, 1957 and Panorpa obliqua Carpenter, 1945 in the V-shaped patter formed by marginal spot and pterostigmal band, but can be readily differentiated from the latter two by the following characters: 1) scutella yellowish and distinctly paler than nota (cf. dark); 2) male gonostylus with basal process bifurcated (cf. unfurcated); and 3) female axis extremely short without distinct apodemes (cf. well-developed with distinct apodemes).

\section{Distribution}

China: Guangdong (Conghua, Shaoguan, Shixing) (Fig. 6).

Panorpa amamiensis Miyamoto \& Makihara, 1984

Figs $1 \mathrm{G}, 6$

Panorpa amamiensis Miyamoto \& Makihara in Miyamoto, 1984: 2, figs 5-7, pl. 3, fig. c (type locality: Mt. Yuwan-dake, Amami-Oshima, Japan).

Panorpa amamiensis - Miyamoto 1988: 42, fig. 3. - Nakamura 2009: 334, figs 1, 4-10.

\section{Diagnosis}

This species is similar to Panorpa longiramina Issiki \& Cheng, 1947 in the greatly reduced wing markings, but can be readily differentiated from the latter by the following characters: 1) wings with reduced basal and pterostigmal bands and marginal spot (cf. only a small spot near pterostigma); and 2) male parameres bifurcated (cf. trifurcated).

\section{Distribution}

Japan: Kagoshima (Amami) (Fig. 6).

Panorpa hiurai Miyamoto, 1985

Fig. 6

Panorpa hiurai Miyamoto, 1985: 199, figs 1-2 (type locality: Bôbukitadani, Mt. Hira, Shiga Prefecture, Japan).

Panorpa hiurai-Miyamoto 1988: 42, fig. 14.

\section{Diagnosis}

This species is characterized by the following characters: 1) wing markings dense, with two reversed Y-shaped patterns and a transverse band between them; 2) male hypovalves with intensely narrowed and truncated apex; and 3) female medigynium with tapering and slightly divergent posterior arms.

\section{Distribution}

Japan: Honshu (Shiga) (Fig. 6).

Panorpa obliquifascia Chou \& Wang, 1987

Fig. 6

Panorpa obliquifascia Chou \& Wang in Chou et al., 1987: 206, fig. 7 (type locality: Mangshan Mountains, Yizhang, Hunan, China). 
Panorpa obliquifascia - Wang \& Hua 2018: 291, figs 3-144-1, 3-144-2.

\section{Diagnosis}

This species can be recognized by the following characters: 1) wing markings slightly reduced with an oblique pterostigmal band; 2) male hypandrium with long and broad hypovalves exceeding apex of gonocoxites; 3 ) male parameres bifurcated with a short glabrous ventral branch and a long bristlebearing dorsal branch; and 4) female medigynium with a very broad dorsal plate and a greatly elongated axis.

\section{Distribution}

China: Guangdong (Nanling Mountains) and Hunan (Mangshan Mountains) (Fig. 6).

\section{Panorpa nudiramus Byers, 2002}

Fig. 6

Panorpa nudiramus Byers, 2002: 253, figs 1-4 (type locality: Lo-ma-wang Shan, Hualien, Taiwan, China).

\section{Diagnosis}

This species can be readily recognized by the following characters: 1) wings nearly devoid of markings; 2) male hypandrium short and not reaching middle of gonocoxites; and 3) male paramere bifurcated with a slender and glabrous ventral branch and a long bristle-bearing dorsal branch.

\section{Distribution}

China: Taiwan (Hualien, Nantou) (Fig. 6).

Panorpa okinawaensis Nakamura, 2009

Figs 1H, 6

Panorpa okinawaensis Nakamura, 2009: 337, figs 2, 11-17 (type locality: Oku, Kunigami Village, Okinawa-jima, Ryukyu Islands, Japan).

\section{Diagnosis}

This species is superficially resembling Panorpa amamiensis Miyamoto \& Makihara, 1984, but can be readily differentiated from the latter by the following characters: in males, 1) gonostylus with basal process bearing two small teeth on mesial edge; 2) paramere bifurcated with a long and stout dorsal branch; 3) aedeagus with developed lateral process of dorsal valves; and in females, and 4) medigynium with axis twice longer than posterior arms.

\section{Distribution}

Japan: Okinawa (Okinawa-jima) (Fig. 6).

\section{Panorpa tokunoshimaensis Nakamura, 2009}

Figs 1I, 6

Panorpa tokunoshimaensis Nakamura, 2009: 340, figs 3, 18-23 (type locality: Tete Path, Amagi Town, Tokuno-shima, Kagoshima Prefecture, Japan). 


\section{Diagnosis}

This species is superficially similar to Panorpa amamiensis Miyamoto \& Makihara, 1984 and Panorpa okinawaensis Nakamura, 2009, but can be readily differentiated from the latter two by the following characters: 1) male paramere bifurcated with both branches not exceeding apex of gonocoxites (cf. exceeding); and 2) female medigynium with axis shorter than half length of posterior arms (cf. longer).

\section{Distribution}

Japan: Ryukyu Islands (Tokuno-shima) (Fig. 6).

Panorpa fengyanga sp. nov.

urn:1sid:zoobank.org:act:ED6669D2-9620-40C1-8B7C-4543B4A79B00

Figs 3, 6

\section{Diagnosis}

This species is very similar to Panorpa obliquifascia Chou \& Wang, 1987 in the oblique pterostigmal band, but can be easily differentiated from the latter by the following characters: 1) meso- and metanotum each with a yellowish mesal stripe (cf. lacking such a stripe); 2) male paramere with dorsal branch bearing very long bristles directing meso-basad (cf. shorter and directing meso-caudad); and 3) female

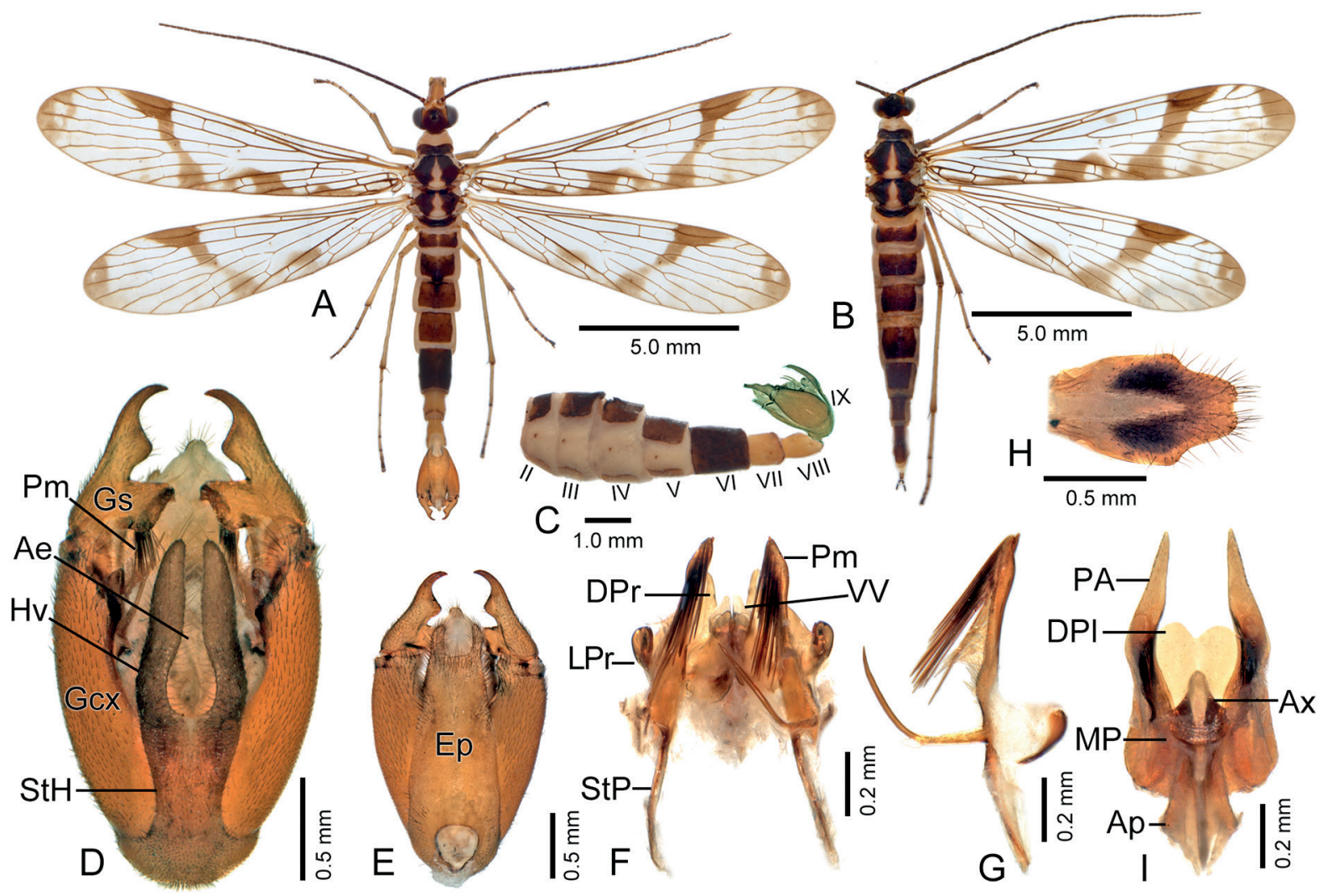

Fig. 3. Panorpa fengyanga sp. nov. A, C-G. Holotype, đ̊ (DALU). B, H-I. Paratype, $q$ (DALU). A-B. Habitus, dorsal view. C. Abdomen, left-lateral view. D-E. Genital bulb, ventral and dorsal views, respectively. F. Aedeagal complex, ventral view. G. Right paramere, right-lateral view. H. Subgenital plate, ventral view. I. Medigynium, ventral view. 
medigynium with axis slightly shorter than posterior arms (cf. longer). The mesal stripes in meso- and metanotum are unique among its relatives.

\section{Etymology}

This species is named after the type locality, Mount Fengyang. Noun in apposition.

\section{Material examined}

Holotype

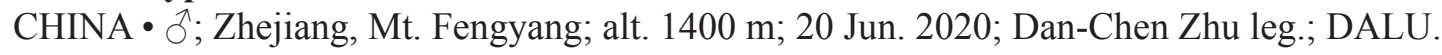

\section{Paratypes}

CHINA $\bullet 1 \hat{\jmath}, 1$ 우 same collection data as for holotype; DALU.

\section{Description}

\section{Male}

HEAD (Fig. 3A). Vertex black medially and yellowish brown near compound eyes. Ocellar triangle black. Rostrum yellowish brown, long and stout. Scape yellowish brown basally and dark brown distally, pedicel dark brown, flagellum black with approximately 35 flagellomeres.

Thorax (Fig. 3A). Pronotum black, bearing 6-8 stout setae along anterior margin. Meso- and metanotum black, each with yellowish, gourd-shaped mesal stripe. Pleura and legs light greyish brown with distal tarsomeres blackish.

WiNGS (Fig. 3A). Membrane hyaline with markings dark brown. In forewing, apical band slightly reduced and usually with hyaline spot; pterostigmal band oblique, with an intact basal branch and detached apical branch; marginal spot inconspicuous; basal band and basal spot fused along hind margin with rounded hyaline spot near ending of $\mathrm{CuP}$; Sc extending approximately at middle of anterior margin; Rs five-branched; 1A ending far beyond origin of Rs. In hindwing, markings similar but more reduced than those of forewing.

Aвdomen (Fig. 3A, C). T1-T5 dark brown, S1-S5 light brown. Notal organ on posterior margin of T3 slightly protruded, semicircular and bearing dense setae posteriorly; postnotal organ on anterior portion of T4 acute and curved dorso-cephalad. A6 black, cylindrical and slightly longer than T5. A7 reddish brown, approximately half as long as A6, cylindrical and slightly beveled apically; A8 similar but slightly longer, thinner, and greatly beveled apically.

Genitalia (Fig. 3D-G). Genital bulb reddish brown, long oval. Epandrium long trapezoidal, with deep terminal emargination and a pair of finger-like processes laterally. Cercus long clavate and blackish. Hypandrium with long and broad basal stalk, and distally split into a pair of hypovalves; hypovalves longer than basal stalk of hypandrium, widely divergent basally and slightly convergent distally, and nearly reaching apex of gonocoxites. Gonocoxites beveled apically; gonostylus approximately half as long as gonocoxites, and bearing an obtuse triangular median tooth and large trapezoidal basal process; small acute process on dorso-apical margin of basal process. Parameres with reduced and detached dorsal bridge, and bifurcated into slender and glabrous ventral branch and bristle-bearing dorsal branch; ventral branch protruding ventrad at basal half and turning caudad in distal half, approximately $2 / 3$ as long as dorsal branch, and tapering into thin and pointed apex; dorsal branch stout, bearing dense bristles on ventral margin; bristles in apical portion extraordinary long and stout, and directing mesobasad. Aedeagus with ventral valves sclerotized, short and subtriangular; dorsal valves very short and inconspicuous; dorsal processes longer and stout; lateral processes elongated and curled mesad. 
Female

Similar to males in general appearance, but with slightly denser wing markings (Fig. 3B).

Genitalia (Fig. 3H-I). Subgenital plate oval and slightly emarginated terminally, with subtriangular process on distal $3 / 5$ of lateral margin; distal $2 / 5$ of subgenital plate narrow, bearing long stout setae. Medigynium with broad dorsal plate; dorsal plate enclosing main plate of medigynium and emarginated in V-shape terminally; main plate poorly developed; posterior arms slightly elbow-shaped and tapering apically; axis slightly shorter than posterior arms with a pair of slightly divergent apodemes; decorated area of axis greatly elongated posteriorly, subtranslucent and subtriangular; between two apodemes acicular process protruded and slightly exceeding apodemes proximally.

\section{Distribution}

China, Zhejiang (Mt. Fengyang) (Fig. 6).

Panorpa zhuohengi sp. nov. urn:1sid:zoobank.org:act:D216769D-9C58-4725-8856-E6C4D0D10516

Figs 4C-D, 5-6

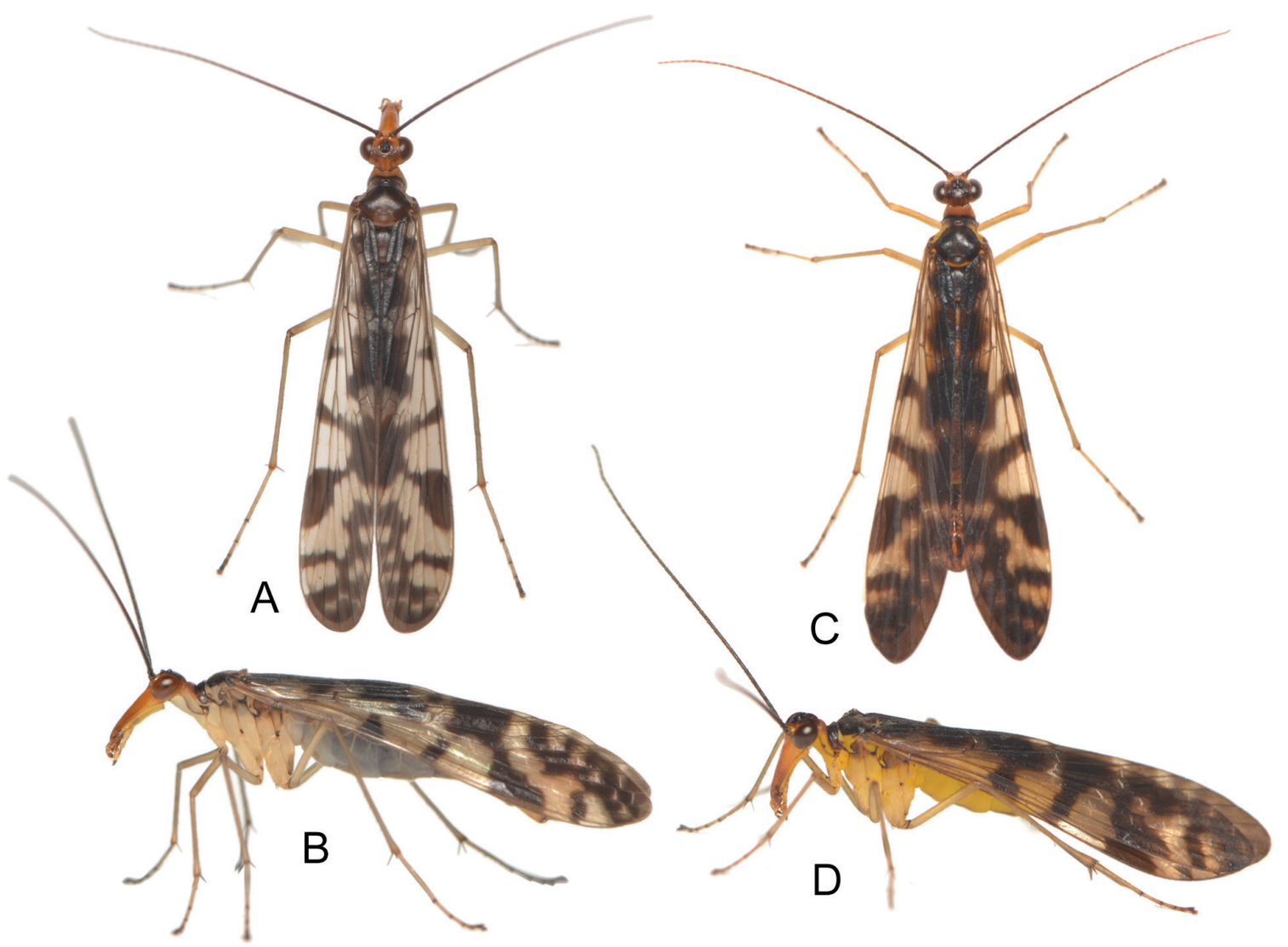

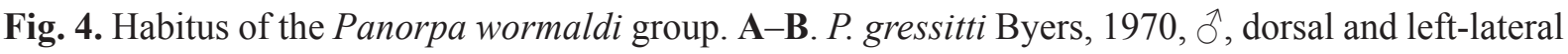
views, respectively. C-D. P. zhuohengi sp. nov., holotype, ठ̊ (DALU) dorsal and left-lateral views, respectively. 


\section{Diagnosis}

This species is superficially similar to Panorpa gressitti Byers, 1970, but can be readily differentiated from the latter by the following characters: in the living insects, 1) body sides light yellow and wing markings dark (cf. body sides greyish and wing markings lighter); in males, 2) gonostylus with basal process stout with a pointed apex (cf. bifurcated); 3) parameres enlarged and bearing long bristles subapically (cf. slender and bearing short bristles); and in females, 4) medigynium with distinct apodemes (cf. lacking). It is also similar to Panorpa obliqua Carpenter, 1945, but can be readily differentiated by the structure of the male parameres.

\section{Etymology}

The new species is named after my friend Mr Zhuo-Heng Jiang, who collected the type specimens. Noun in the genitive case.

\section{Material examined}

\section{Holotype}

CHINA • O'; Guangdong, Fengkai, Heishiding (Dark Rock Peak); alt. 200 m; 15 Apr. 2019; Zhuo-Heng Jiang leg.; DALU.

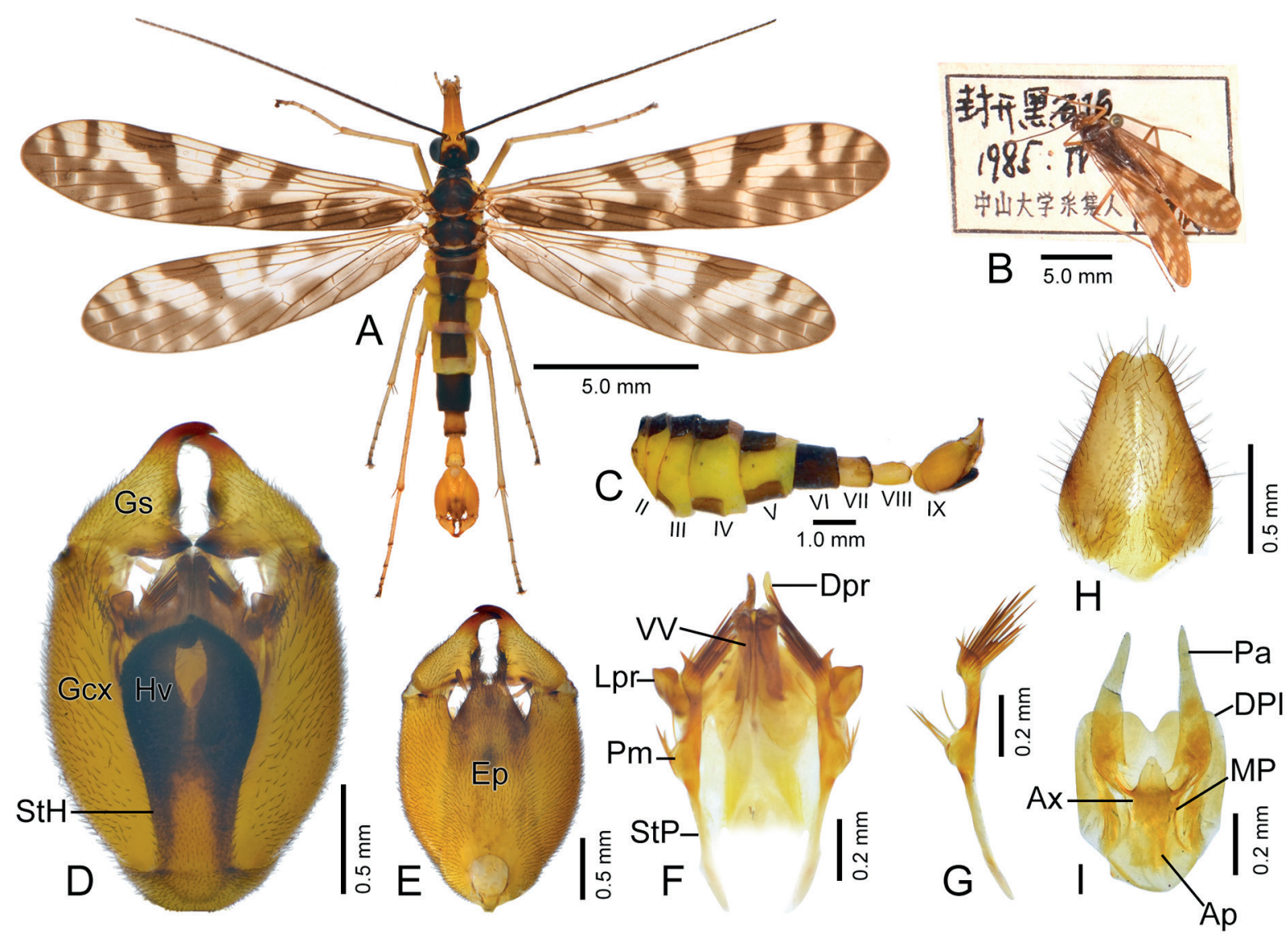

Fig. 5. Panorpa zhuohengi sp. nov. A, C-G. Holotype, $ð$ (DALU). B, H-I. Paratype, $q$ (SYSU). A-B. Habitus, dorsal view. C. Abdomen, left-lateral view. D-E. Genital bulb, ventral and dorsal views, respectively. F. Aedeagal complex, ventral view. G. Left paramere, ventral view. H. Subgenital plate, ventral view. I. Medigynium, ventral view. 


\section{Paratypes}

CHINA $-3 \widehat{\partial}$; same collection data as for holotype; DALU $\bullet 1$; ; same locality as for preceding; 17-18 Apr. 2004; Chun-Tian Zhang leg.; SYSU • 2 \%; same locality as for preceding; 10 Apr. 1985; Zhen-Yao Chen leg.; SYSU.

\section{Description}

\section{Male}

HEAD (Fig. 5A). Vertex black medially and yellowish brown near compound eyes and antennal sockets. Ocellar triangle black. Rostrum yellowish brown, long and stout. Scape yellowish brown basally and dark brown distally, pedicel dark brown, flagellum black with approximately 38 flagellomeres.

Thorax (Fig. 5A). Pronotum black, bearing 6-8 stout setae along anterior margin. Meso- and metanotum black, each with yellowish, gourd-shaped mesal stripe. Pleura light yellow. Legs yellowish brown with distal tarsomeres blackish.

WINGS (Fig. 5A). Membrane hyaline, slightly tinged with yellowish brown. Markings dense and dark brown. In forewing, apical band broad and usually with series of hyaline spots along apical cross-veins; pterostigmal band oblique, with an intact basal branch and detached apical branch; apical branch fused with posterior portion of apical band; marginal spot elongated posteriorly and fused with pterostigmal band and forming V-shaped pattern; basal band broad; basal spot fused with basal band along hind margin with few hyaline spots along basal cross-veins; Sc extending approximately at middle of anterior margin; Rs five-branched; 1A ending far beyond origin of Rs. In hindwing, markings similar but more reduced than those of forewing.

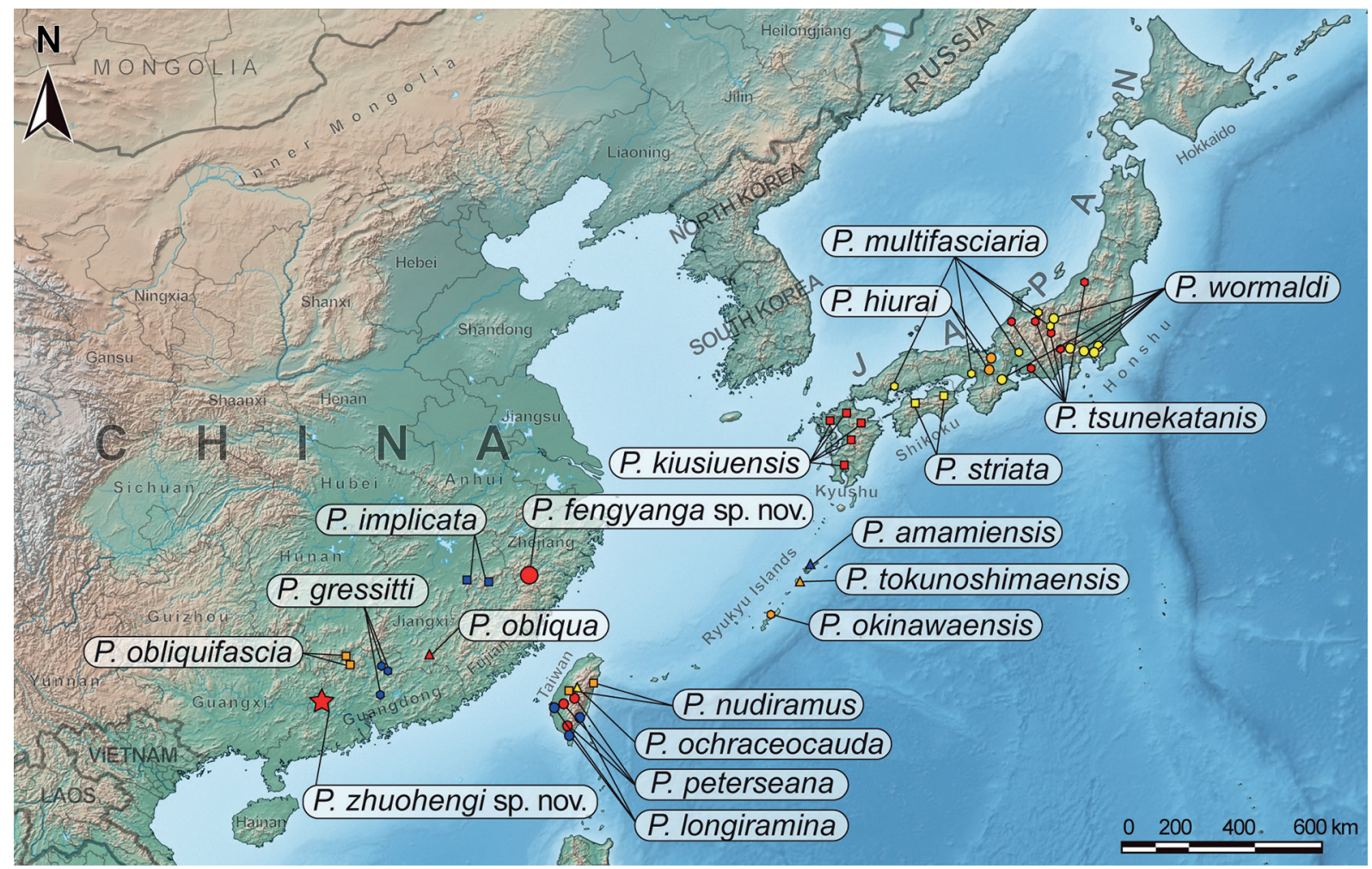

Fig. 6. Distribution of the Panorpa wormaldi group. 
Abdomen (Fig. 5A, C). T1-T5 dark brown, S1-S5 brown, pleural membrane yellow. Notal organ on posterior margin of $\mathrm{T} 3$ slightly protruded, semicircular and bearing dense setae posteriorly; postnotal organ on anterior portion of T4 acute and curved dorso-cephalad. A6 black, cylindrical and slightly longer than T5. A7 yellowish brown and blackish on apical margin, approximately half as long as A6, cylindrical and slightly beveled apically; A8 similar but slightly longer, thinner, and greatly beveled apically.

Genitalia (Fig. 5D-G). Genital bulb yellowish brown, oval. Epandrium long trapezoidal, greatly constricted in distal portion, with deep terminal emargination and a pair of finger-like processes laterally. Cercus long clavate and blackish. Hypandrium with long and broad basal stalk, and distally split into a pair of hypovalves; hypovalves slightly shorter than basal stalk of hypandrium, widely divergent basally and slightly convergent distally, and not reaching lateral processes of aedeagus. Gonocoxites beveled apically; gonostylus approximately half as long as gonocoxites, and bearing an obtuse triangular median tooth and stout basal process. Parameres each with slender basal stalk, and greatly enlarged basally and subapically; four long stout bristles on outer margin of basally enlarged portion; and dozens of longer bristles on inner side of subapically enlarged portion; apex of paramere pointed and slightly curving laterad. Aedeagus with ventral valves sclerotized and columnar; dorsal valves very short and inconspicuous; dorsal processes longer and finger-like; lateral processes slightly elongated, stout and nearly truncated with an indistinct terminal emargination.

\section{Female}

Similar to males in general appearance, but with slightly denser wing markings (Fig. 5B).

Genitalia (Fig. 5H-I). Subgenital plate subtriangular with shallow terminal emargination, and bearing sparse long setae marginally. Medigynium with broad dorsal plate emarginated in V-shape terminally; posterior arms slightly arcuate and tapering distally; axis shorter than posterior arms with short and stout apodemes proximally; decorated area of axis greatly elongated posteriorly, subtranslucent and subtriangular.

\section{Distribution}

China: Guangdong: Fengkai (Fig. 6).

\section{Key to species of the Panorpa wormaldi group}

\section{Males \\ 19 species}

1. Wing markings greatly reduced and covering less than $1 / 5$ area of wing

- Wing markings well-developed and covering at least $1 / 5$ area of wing .....

2. Hypandrium at least extending to middle of gonocoxites apically; parameres trifurcated .............. 3

- Hypandrium greatly shortened and not reaching middle of gonocoxites apically; parameres bifurcated

3. Paramere concealed in gonocoxital cavity, with dorsal branch bearing short microtrichia along inner margin P. ochraceocauda Issiki, 1927

- Paramere extending beyond apex of gonocoxites, with dorsal branch bearing long spines along inner margin P. longiramina Issiki \& Cheng, 1947

4. Paramere with ventral branch glabrous 5

- Paramere with ventral branch bearing long bristles 6 
5. Paramere with dorsal branch greatly curved and S-shaped

P. amamiensis Miyamoto \& Makihara, 1984

- Paramere with dorsal branch straight ..P. nudiramus Byers, 2002

6. Paramere with dorsal branch greatly elongated, twice longer than ventral branch and exceeding apex of gonocoxites P. okinawaensis Nakamura, 2009

- Paramere with dorsal branch shorter than ventral branch and not exceeding apex of gonocoxite

..P. tokunoshimaensis Nakamura, 2009

7. Wings with marginal spot greatly elongated, fused with pterostigmal band and forming a distinct V-shaped pattern

- Wings lacking a V-shaped pattern . .11

8. Genital bulb long oval (approximately twice as long as wide); hypovalves longer than basal stalk of hypandrium P. implicata Cheng, 1957

- Genital bulb bold oval (approximately $1.7 \times$ as long as wide); hypovalves shorter than basal stalk of hypandrium

9. Gonostylus with basal process bifurcated into two small teeth; paramere S-shaped

- Gonostylus with basal process stout and simple; parameres relatively straight

P. gressitti Byers, 1970

10. Parameres curved inward and bearing short bristles subapically

- Parameres curved laterad and bearing long bristles subapically

P. obliqua Carpenter, 1945 P. zhuohengi sp. nov.

11. Pterostigmal band with detached apical branch and forming a distinct oblique band. 12

- Pterostigmal band with apical branch intact 15

12. Vertex yellow with a trident-shaped black pattern; paramere trifurcated

P. peterseana Issiki, 1927

- Vertex brown to black, and lacking a trident-shaped black patter; paramere bifurcated 13

13. Meso- and metanotum each with a yellowish mesal stripe P. fengyanga sp. nov.

- Meso- and metanotum lacking a yellowish mesal stripe 14

14. Hypovalves exceeding apex of gonocoxites; parameres with dorsal branch extending to middle of gonostylus

P. obliquifascia Chou \& Wang, 1987

- Hypovalves extending to $2 / 3$ of gonocoxites; parameres with dorsal branch slightly exceeding apex of gonocoxites

P. kiusiuensis Issiki, 1929

15. Hypovalves with intensely narrowed and truncated apex P. hiurai Miyamoto, 1985

- Hypovalves with tapering and relatively rounded apex 16

16. Hypandrium short, with apex of hypovalves not extending to apex of gonocoxites; hypovalves shorter than basal stalk of hypandrium

- Hypandrium long, with apex of hypovalves extending to apex of gonocoxites; hypovalves longer than basal stalk of hypandrium

17. Wing markings slightly reduced with two reversed, separated Y-shaped pattern

- Wing markings dense and reticulate, with two reversed Y-shaped pattern connected by an additional transverse stripe

P. striata Miyaké, 1908 
18. Wings with pterostigmal band represented by two anteriorly connected Y-shaped pattern; parameres unfurcated and short, not exceeding apex of gonocoxites ................P. wormaldi MacLachlan, 1875

- Wings with marginal spot fused with pterostigmal band and forming an H-shaped pattern; parameres bifurcated with dorsal branch extending to middle of gonostylus P. tsunekatanis Issiki, 1929

\section{Females}

14 species; . kiusiuensis, $P$. ochraceocauda, P. multifasciaria, $P$. nudiramus and $P$. wormaldi unknown.

1. Wing markings greatly reduced and covering less than $1 / 5$ area of wing ...................................... 2

- Wing markings well-developed and covering at least $1 / 5$ area of wing ........................................... 5

2. Axis extremely shortened, shorter than half length of posterior arms

P. tokunoshimaensis Nakamura, 2009

- Axis in medigynium longer than half length of posterior arms

3. Axis in medigynium greatly elongated, longer than posterior arms

P. okinawaensis Nakamura, 2009

- Axis approximately as long as or shorter than posterior arms

4. Axis in medigynium shorter than posterior arms ........P. amamiensis Miyamoto \& Makihara, 1984

- Axis in medigynium approximately as long as posterior arms P. longiramina Issiki \& Cheng, 1947

5. Wings with marginal spot greatly elongated, fused with pterostigmal band and forming a distinct V-shaped pattern

- Wings lacking a V-shaped pattern

6. Axis in medigynium lacking apodemes

P. gressitti Byers, 1970

- Axis in medigynium bearing apodemes 7

7. Axis longer than posterior arms P. implicata Cheng, 1957

- Axis shorter than posterior arms

8. Separated spot anterior to ORs; posterior arms of medigynium narrow

P. obliqua Carpenter, 1945

- Continuous band across ORs; posterior arms of medigynium broad at base and tapering towards acute apex

9. Pterostigmal band with detached apical branch and forming a distinct oblique band 10

- Pterostigmal band with apical branch intact

10. Vertex yellow with a trident-shaped black pattern

P. peterseana Issiki, 1927

- Vertex brown to black, and lacking a trident-shaped black pattern

11. Meso- and metanotum each with a yellowish mesal stripe

P. fengyanga sp. nov.

- Meso- and metanotum lacking a yellowish mesal stripe P. obliquifascia Chou \& Wang, 1987

12. Wing markings reticulate and lacking recognizable Y-shaped patterns

P. tsunekatanis Issiki, 1929

- Wing markings with two reversed Y-shaped patterns and a transverse band between them 13

13. Posterior arms with broad lateral projection in distal half; apodemes slightly divergent

- Posterior arms lacking lateral projection; apodemes greatly divergent .... P. hiurai Miyamoto, 1985 


\section{Discussion}

By describing two new species, the species number of the Panorpa wormaldi group is updated from 17 to 19. According to recent molecular phylogenetic analyses (Whiting 2002; Hu et al. 2015), Panorpa striata Miyaké, 1908, a member of this group is closely related to members of several eastern Asian groups, such as the Panorpa japonica group sensu Issiki, 1933 and the Panorpa nikkoensis group (= the P. leucoptera group sensu Issiki, 1933, because Panorpa nikkoensis Miyaké, 1908 was synonymized with Panorpa leucoptera Uhler, 1858 due to misidentification, but recently revalidated by Miyamoto \& Nakamura 2008). However, other species in this group lack comprehensive phylogenetic analysis, and their systematic position in the Panorpidae remains unresolved to date.

Presumably, members in the $P$. wormaldi group likely form a monophyletic group, supported by some synapomorphies, such as the greatly elongated lateral processes in the male aedeagus, and a dorsal plate in the female medigynium. In addition, the living insects in this species group hold their wings roof-like over the abdomen (different from the more common V-shape, Ennos \& Wootton 1989; Wang \& Hua 2018, 2021), giving a great resemblance to Furcatopanorpa longihypovalva (Hua \& Cai, 2009) and Panorpa bicornuta MacLachlan, 1887. However, more or less, some distantly related species in this family also hold wings roof-like, such as Panorpa cornigera MacLachlan, 1887, Panorpa lugubris Swederus, 1787, and Neopanorpa salai Navás, 1929. These facts suggest that the roof-like wing posture is likely nonhomologous and independently developed several times in Panorpidae.

In the $P$. wormaldi group, several species were observed active among dense bushes and grasses (the first author's observations, $P$. striata, $P$. gressitti, and $P$. zhuohengi sp. nov.), and $P$. peterseana was reported foraging among tree-canopy blossoms (Bicha et al. 2020). These species are different from many other scorpionflies which hold their wings in a V-shape, and usually sit on the top surface of ground vegetations or the ground (Bicha et al. 2020). When captured, some species (P. gressitti, P. striata, and $P$. zhuohengi sp. nov.) prefer to rapidly crawl towards the light in the net, rather than fly away as many other scorpionflies do to escape. By holding their wings roof-like, members in the $P$. wormaldi group have their bodies greatly narrowed, and likely received a great flexibility when they are crawling back and forth among the dense vegetation.

The distributional pattern of the $P$. wormaldi group provide us a valuable point of view to study the relationship of panorpid fauna between China and Japan. According to Tojo et al. (2017), the geological history played an important role for the high biodiversity and endemism of Japan. The southwestern part of Japan (Kyushu, Shikoku and western Honshu) was considered to begin to split from the Korean Peninsula around $20 \mathrm{Ma}$ (Otofuji et al. 1985). Members of the $P$. wormaldi group are ranged in southeastern mainland China, Taiwan, Ryukyu Islands, and three main Japanese islands, but are not yet recorded from the Korean Peninsula and the island of Hokkaido. The southwestern parts of Japan and the southeastern coast of China were once connected due to the lowered sea level, thus provided a land bridge for the faunal dispersal during the Last Glacial Maximum (Tojo et al. 2017). More studies are required to decipher the evolutionary and biogeographical history of the $P$. wormaldi group.

\section{Acknowledgments}

The authors would like to thank Messrs Zhuo-Heng Jiang and Dan-Chen Zhu for collecting and donating the specimens. We also thank Prof Hong Pang and Dr Bing-Lan Zhang for arranging the loan of the specimens in SYSU. Our appreciation also goes to two anonymous reviewers for their valuable comments on the manuscript. Special thanks are due to Dr Hao Xu for interpreting the type locality of Panorpa obliqua. This research was financially supported by the Tianlong Entomological Foundation, and the Starting Foundation for the High-level Talents, Dali University (Grant No. KY2096124040). 


\section{References}

Bicha W., Chiu Y., Nakamura T. \& Almquist D. 2020. Unusual scorpionfly (Mecoptera: Panorpidae) collecting techniques. Proceedings of the Entomological Society of Washington 122 (4): 1001-1004. https://doi.org/10.4289/0013-8797.122.4.1001

Byers G.W. 1970. New and little known Chinese Mecoptera. Journal of the Kansas Entomological Society 43 (4): 383-394.

Byers G.W. 2002. Mecoptera from Taiwan. Journal of the Kansas Entomological Society 75 (4): 252258.

Carpenter F.M. 1945. Panorpidae from China (Mecoptera). Psyche 52 (1-2): 70-78. https://doi.org/10.1155/1945/69797

Cheng F.Y. 1957. Revision of the Chinese Mecoptera. Bulletin of the Museum of Comparative Zoology at Harvard College 116 (1): 1-118.

Chou I., Wang S.-M., Li Z.-D. \& Tong X.-W. 1987. New species of Mecoptera from Hunan Province (I) - Studies on the classification of Chinese Mecoptera (III). Entomotaxonomia 9 (3): 201-212.

Enderlein G. 1910. Über die Phylogenie und die Klassifikation der Mecopteren unter Berücksichtigung der fossilen Formen. Zoologischer Anzeiger 35: 385-399.

Ennos A.R. \& Wootton R.J. 1989. Functional wing morphology and aerodynamics of Panorpa germanica (Insecta: Mecoptera). Journal of Experimental Biology 143: 267-284.

https://doi.org/10.1242/jeb.143.1.267

Esben-Petersen P. 1915. A synonymic list of the order Mecoptera together with descriptions of new species. Entomologiska Meddelelser 10: 216-242.

Esben-Petersen P. 1921. Mecoptera. Monographic revision: Collections Zoologiques du Baron Edm. de Selys Longchamps. Catalogue Systématique et Descriptif 5: 1-172.

Hsu T.-C., Wu W.-J. \& Chou L.-Y. 1999. A check list of Mecoptera (Insecta) of Taiwan. Journal of Agricultural Researches of China 48 (2): 149-155.

Hu G.-L., Yan G., Xu H. \& Hua B.-Z. 2015. Molecular phylogeny of Panorpidae (Insecta: Mecoptera) based on mitochondrial and nuclear genes. Molecular Phylogenetics and Evolution 85: 22-31.

https://doi.org/10.1016/j.ympev.2015.01.009

Issiki S. 1927. New and rare species of Mecoptera from Corea, Formosa and Japan. Insecta Matsumurana 2(1): $1-12$.

Issiki S. 1929. Descriptions of new Mecoptera from the Japanese Empire. Transactions of the Natural History Society of Formosa 19: 260-314.

Issiki S. 1933. Morphological studies on the Panorpidae of Japan and adjoining countries and comparison with American and European forms. Japanese Journal of Zoology 4 (4): 315-416.

Issiki S. 1965. Notes on some Mecoptera from Formosa. Special Bulletin of the Lepidopterological Society of Japan 1: 245.

Issiki S. \& Cheng F.Y. 1947. Formosan Mecoptera with descriptions of new species. Memoirs of the College of Agriculture, National Taiwan University 1 (4): 1-17.

MacLachlan R. 1875. A sketch of our knowledge of the neuropterous fauna of Japan (excluding Odonata and Trichoptera). Transactions of the Entomological Society of London 23 (2): 167-190.

https://doi.org/10.1111/j.1365-2311.1875.tb01906.x 
Mickoleit G. 1975. Die Genital- und Postgenitalsegmente der Mecoptera-Weibchen (Insecta, Holometabola) I. Das Exoskelet. Zeitschrift für Morphologie der Tiere 80: 97-135.

Mickoleit G. 1976. Die Genital- und Postgenitalsegmente der Mecoptera-Weibchen (Insecta, Holometabola) II. Das Dach der Geritalkammer. Zoomorphologie 85: 133-156. https://doi.org/10.1007/BF00995408

Miyaké T. 1908. A list of Panorpidae of Japan, with descriptions of ten new species. Bulletin of the College of Agriculture, Tokyo Imperial University 8: 1-13.

Miyaké T. 1910. A further contribution towards the knowledge of the Panorpidae of Japan. Journal of the College of Agriculture of the Imperial University of Tokyo 2: 183-205.

Miyaké T. 1913. Studies on the Mecoptera of Japan. Journal of the College of Agriculture, Imperial University of Tokyo 4: 265-400.

Miyamoto S. 1984. New species and subspecies of the Meoptera in Japan (Insecta). Journal of Chikushi Jogakuen Junior College 19: 1-16.

Miyamoto S. 1985. Description of a new species of the genus Panorpa Linnaeus (Mecoptera, Panorpidae). Kontyû 53: 199-201.

Miyamoto S. 1988. A checklist of the Panorpidae. Panorpodes 8/9: 39-49.

Miyamoto S. 1994. Scorpion-flies of the Shikoku Mountains, with descriptions of two new species of the genus Panorpa Linnaeus (Mecoptera: Panorpidae). Transactions of the Shikoku Entomological Society 20: 3-4.

Miyamoto S. \& Nakamura T. 2008. Mecoptera. In: Hirashima Y. \& Morimoto K. (eds), Iconographia Insectorum Japonicorum Colore Naturali Edita. III: 229-233. Hokiryukan, Tokyo, Japan.

Nakamura T. 2009. A redescription of Panorpa amaniensis and descriptions of its closely allied two new species from the Ryukyu Islands, Japan (Mecoptera, Panorpidae). Japanese Journal of Systematic Entomology 15: 333-342.

Otofuji Y.-I., Matsuda T. \& Nohda S. 1985. Opening mode of the Japan Sea inferred from the palaeomagnetism of the Japan Arc. Nature 317 (6038): 603-604. https://doi.org/10.1038/317603a0

Penny N.D. \& Byers G.W. 1979. A check-list of the Mecoptera of the world. Acta Amazonica 9 (2): 365-388. https://doi.org/10.1590/1809-43921979092365

Suzuki T. \& Suzuki N. 2015. The distribution range of the scorpion fly, Panorpa multifasciaria Miyake, 1910, in Nagano Prefecture. New Entomologist 64 (3, 4): 51-53.

Tojo K., Sekiné K., Takenaka M., Isaka Y., Komaki S., Suzuki T. \& Schoville S.D. 2017. Species diversity of insects in Japan: Their origins and diversification processes. Entomological Science 20 (1): 357-381. https://doi.org/10.1111/ens.12261

Wang J.-S. \& Hua B.-Z. 2018. A Color Atlas of the Chinese Mecoptera. Henan Science and Technology Press, Zhengzhou.

Wang J.-S. \& Hua B.-Z. 2021. Morphological phylogeny of Panorpidae (Mecoptera: Panorpoidea). Systematic Entomology 46 (3): 526-557. https://doi.org/10.1111/syen.12474

Whiting M.F. 2002. Mecoptera is paraphyletic: multiple genes and phylogeny of Mecoptera and Siphonaptera. Zoologica Scripta 31 (1): 93-104. https://doi.org/10.1046/j.0300-3256.2001.00095.x

Willmann R. 1989. Evolution und phylogenetisches System der Mecoptera (Insecta: Holometabola). Abhandlungen der Senckenbergischen Naturforschenden Gesellschaft 554: 1-153. 
Manuscript received: 28 April 2021

Manuscript accepted: 6 December 2021

Published on: 11 February 2022

Topic editor: Nesrine Akkari

Desk editor: Eva-Maria Levermann

Printed versions of all papers are also deposited in the libraries of the institutes that are members of the EJT consortium: Muséum national d'histoire naturelle, Paris, France; Meise Botanic Garden, Belgium; Royal Museum for Central Africa, Tervuren, Belgium; Royal Belgian Institute of Natural Sciences, Brussels, Belgium; Natural History Museum of Denmark, Copenhagen, Denmark; Naturalis Biodiversity Center, Leiden, the Netherlands; Museo Nacional de Ciencias Naturales-CSIC, Madrid, Spain; Real Jardín Botánico de Madrid CSIC, Spain; Zoological Research Museum Alexander Koenig, Bonn, Germany; National Museum, Prague, Czech Republic. 